\title{
The impact of testosterone levels on J-wave patterns observed in healthy Turkish males
}

\author{
Burak Hünük॰ \\ Department of Cardiology, Yeditepe University School of Medicine, Istanbul, Turkey
}

\section{ABSTRACT}

Objectives: Early-repolarization (ER) and Brugada-type-ECG-patterns (BTEP) have recently been grouped under a common terminology called "J-wave patterns" (JWP) and have been associated with an increased risk of sudden-cardiac-death. Scarce data is present about the male dominance in JWP and the probable effects of gonadal hormones on cardiac ion-channel functions. We sought to evaluate the relationship of testosteronelevels and the presence of JWP in healthy Turkish-males.

Methods: One hundred eighty-five healthy male volunteers between $\geq 18$ to $\leq 50$ years old without any cardiac disorders were evaluated. ECG, blood biochemistry and total testosterone levels were obtained together with thorough physical examination. Subjects with complete-bundle-branch-block, non-sinus-rhythms and any abnormality on cardiac examination were excluded from the study. BTEP was searched according to the EHRA/HRS 2016 Consensus Conference on V1-V3. ER on ECG was defined as J-point elevation of $\geq 0.1$ $\mathrm{mV}$ in $\geq 2$ leads in the inferior (II, III, aVF) (Inferior ER), lateral (DI, aVL, V4-6) (Lateral ER) or both (Inferolateral ER).

Results: A total of 179 subjects (mean age $34.9 \pm 7.9$ years) were included in our analyses. Three BTEP $(1.7 \%)$ and 45 ER (26\%) were detected. 22 were lateral (49\%), 13 inferior (29\%) and 10 were (22\%) inferolateral ER. JWP $(+)$ subjects $(\mathrm{n}=48,27 \%)$ were demonstrating significantly lower basal heart rates $(73.9 \pm 11 \mathrm{bpm}$ vs $68.4 \pm 10.3 \mathrm{bpm}, p=0.001)$ and longer PR intervals $(153.9 \pm 20.3 \mathrm{~ms}$ vs $163.3 \pm 21.6 \mathrm{~ms}, p=0.01)$. JWP $(+)$ subjects had significantly higher testosterone levels compared with the ones without $(485.5 \pm 128.3 \mathrm{ng} / \mathrm{dl} \mathrm{vs}$ $559.3 \pm 167.7, p<0.001)$. In the subgroup analyses, BTEP and inferior/inferolateral ER patterns were significantly associated with higher testosterone levels compared with the JWP (-) population, while testosterone levels of subjects with lateral ER was not significantly higher. Electrolytes and blood chemistry values were non-significant between JWP + and - subjects. In the ROC analysis, the cut-off value for predicting the presence of a JWP on ECG was $629 \mathrm{ng} / \mathrm{dl}$ with a sensitivity of $44 \%$ and specificity of $86 \%$ [AUC $=0.66$ (95\% CI: 0.56-0.75) $p=0.001]$. In multivariate analysis, total testosterone level $>629 \mathrm{ng} / \mathrm{dl}$ was significantly predicting a JWP on ECG, even outperforming age and hs-CRP levels with an OR of 4.57 (95\% CI 1.910$10.9, p=0.001)$.

Conclusions: Testosterone might be associated with the male predominance observed in the JWP. More malignant inferior/inferolateral ER seems to be mainly associated with the high testosterone levels in Turkish male population. This finding might be attributed to the previously demonstrated effects of testosterone on cardiac ion-channel functions, especially outward-K channels.

Keywords: Electrocardiogram, j-wave pattern, male, testosterone 
$\mathrm{E}$ lectrocardiographically the point where the QRS complex ends and a prominent ST segment starts is called the $\mathrm{J}$ point [1]. In 1953, Osborn et al. [2] defined $\mathrm{J}$ points in the form of a positive deflection from the isoelectric line in experimental hypothermia which were clinically referred to as "Osborn Waves" and then as "Jwaves". The fact that such changes are frequently observed in the young male population also led to the association of J waves with ST-segment elevation as a benign electrocardiographic finding called "Early Repolarization Variant/ Pattern (ER) [3-5]. In recent years, several population-based studies in which $\mathrm{J}$ waves such as inferolateral ER and Brugada type ECG patterns (BTEP) were determined to be associated with an increased sudden cardiac death (SCD) and lethal ventricular arrhythmias (VA) have been published worldwide [6-11]. Although they have different diagnostic criteria, clinical phenotypes such as Brugada Syndrome (BS) and Early Repolarization Syndrome (ERS) which are associated with specific $J$ wave findings / J wave patterns with different dispersion of repolarization mechanisms in different regions of the heart and causing life-threatening arrhythmias, have been grouped under a new terminology and concept as "J Wave Syndromes" in recent years $[12,13]$. National and international research on the etiology, mechanisms and frequency of $\mathrm{J}$ wave syndromes are increasing and new studies are designed to recognize this assumingly rare but fatal syndrome earlier and reveal its physiopathology [13-16]. In these studies, the frequencies of observed J wave patterns (JWP) were highly heterogenous between $3-5 \%$ to $0.1 \%$ in the general population according to the race, age and comorbidities of the study population, however constantly and significantly found to be highest in the male sample groups irrespective of the other features of the study population $[10,12,13]$. Even though, the repolarization theory is the most popular explanation about the observed transmural epi-endocardial voltage gradient in JWPs, contemporary findings in electroanatomic mapping/ablation studies state that JWPs might also occur because of delayed depolarization on the related segments $[13,17]$.

Although $\mathrm{J}$ wave syndromes such as autosomal dominant BS genetically demonstrate an equal transition in males and females, it is extremely rare to have a phenotypic appearance in women compared with men (1:10 ratio) $[10,12,18]$. The presence of more
Ito channels in the male right ventricular outflow tract and right ventricular epicardium is shown to be one of the reasons, but some aspects of the BS clinic cannot be fully explained in this way, such as its clinical preponderance after the puberty and attenuation of the malignant clinical features after the 6th decade in males $[10,18,19]$. In research studies, testosterone and dihydrotestosterone levels effected the $\mathrm{Na}, \mathrm{Ca}$ and $\mathrm{K}$ (especially Ito) channels forming the action potential dome leading to a repolarization dispersion similarly observed in J-wave syndromes [20]. It was also shown that the Brugada pattern was lost in men who underwent orchiectomy due to prostate cancer [21]. Regarding the ER patterns, young athletic male predominance might give a clue about the probable contributing effects of higher testosterone levels to the ER phenomenon which share similar ionic and clinical characteristics with BS [12].

Hence, we aimed to evaluate the relationship of testosterone-levels and the presence/distribution and clinical features of JWP in healthy Turkish-males and compared the effects with other clinical and laboratory parameters which might contribute to the frequency of JWP such as age and inflammation parameters.

\section{METHODS}

One hundred eighty-five healthy male volunteers between $\geq 18$ to $\leq 50$ years old without any diagnosed cardiac/systemic history and no family history of SCD were prospectively and consecutively evaluated for inclusion to the study. The study complies with the Declaration of Helsinki, patients provided signed informed consent and the local ethical committee approval obtained. Supine 12-lead surface ECG, complete blood count, high sensitivity (hs)-CRP, renal/thyroid function tests and total testosterone levels obtained together with thorough physical examination. Subjects with complete bundle branch blocks on ECG, non-sinus rhythms and any abnormal findings on cardiac examination were excluded from the study.

\section{Electrocardiographic Assessment}

The 12-lead ECGs were recorded at $25 \mathrm{~mm} / \mathrm{s}$ with a calibration of $10 \mathrm{~mm} / \mathrm{mV}$ (Nihon Kohden, Tokyo, Japan) and uploaded on the hospital ECG database at 
300 DPI. These images were amplified x10 and then baseline heart rates, PR, QRS, QTc (Bazett) intervals were manually measured by electronic calipers. The presence of a lateral (I, aVL, V5-V6), inferior (II, III, aVF) or inferolateral (II, III, aVF, I, aVL, V5-V6) ER was defined as an evident J-point elevation of at least $1 \mathrm{~mm}(0.1 \mathrm{mV})$ above the isoelectric line in at least two consecutive leads with either QRS slurring (i.e. a smooth transition from the end QRS to the beginning of ST-segment) or notching [positive deflection (Jwave) occurring immediately after a positive QRS complex at the onset of the ST-segment] according to the most recently proposed terminology from the latest international consensus documents for the ECG definition of ER [13, 18], and "J peak" was accepted as "J point" denoting the peak of a notch or onset of a slur. BTEPs were searched according to the EHRA/HRS 2016 Consensus Conference on V1-V3 leads $[10,18]$. All the ECGs were analysed by the author in a blinded fashion for the laboratory findings of the patients with borderline results being reassessed by another experienced cardiologist.

\section{Blood Tests and Analysis}

Venous blood samples were drawn with patients after they rest supine for about 15 min prior to sampling. Samples were drawn atraumatically without venous stasis through a 21-gauge cannula inserted into an antecubital vein using ethylenediamine tetraacetic acid containing monovettes (Sarstedt, Nuembrecht, Germany), and transferred immediately to the laboratory to be centrifuged. Hs-CRP level was measured on Cobas Integra 400 Plus using a latex particle-enhanced immunoturbidimetric assay following the manufacturer's instructions (Roche Diagnostics, Indianapolis, IN). Testosterone levels were determined using electrochemiluminescence immunoassay method and an auto-analyser (Cobas 6000, E 601 Roche Diagnostics, GmbH, Mannheim, Germany). The complete blood counts were evaluated using an auto-analyzer Sysmex XT-1800i Haematology Analyzer (Sysmex Corporation, Kobe, Japan). The remaining routine biochemistry parameters have been determined by the core laboratory.

\section{Statistical Analysis}

Continuous variables are expressed as mean $\pm \mathrm{SD}$ (if the parameter is normally distributed) or standard error of mean $(\mathrm{SEM} \pm \mathrm{SD})$ whichever is suitable. If appropriate, they were compared using the Student's t-test. Categorical variables are expressed as numbers

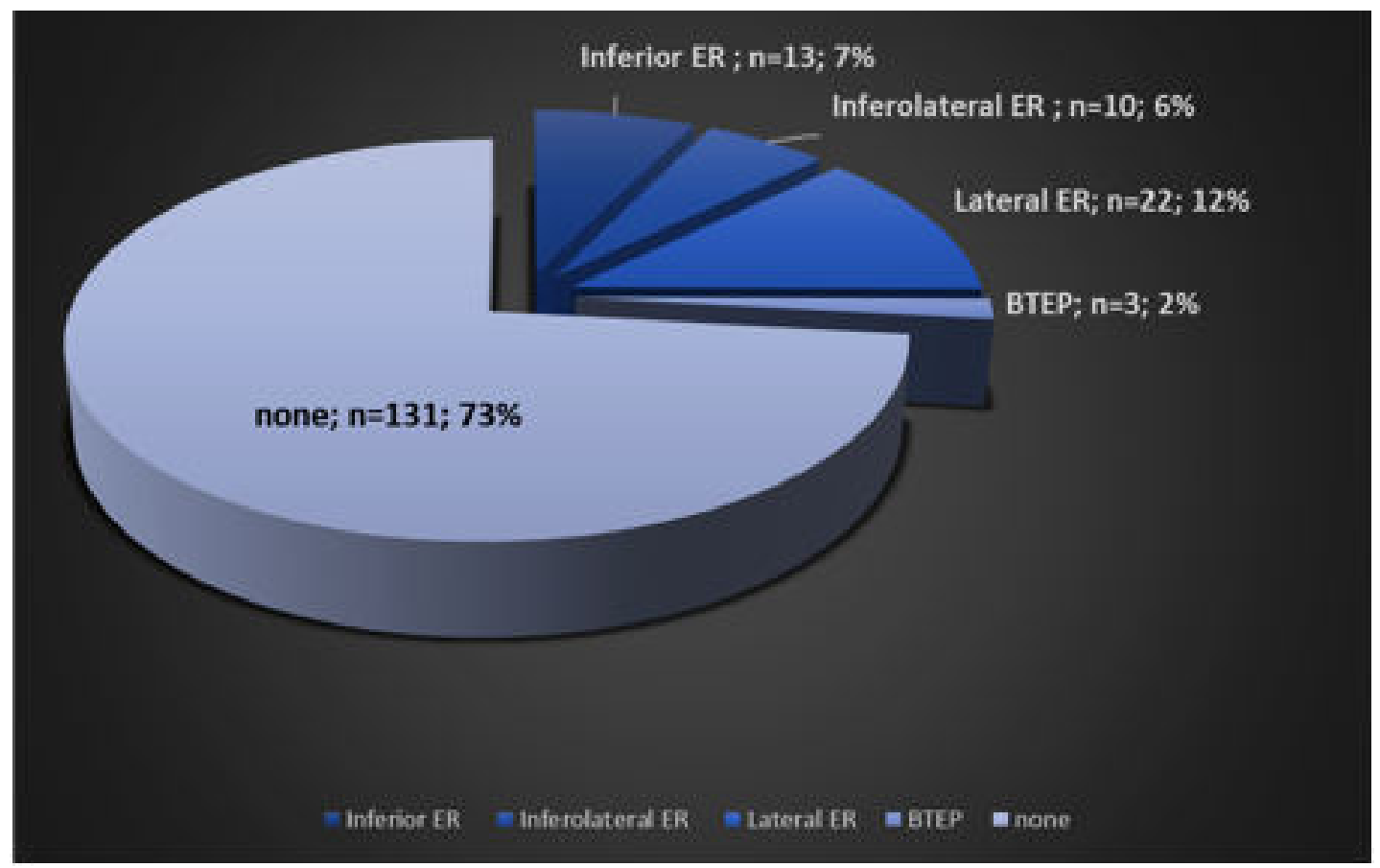

Fig. 1. Prevalence of the J-wave patterns in study population. $\mathrm{ER}=$ Early repolarization pattern, $\mathrm{BTEP}=\mathrm{Brugada}$ type $\mathrm{ECG}$ pattern. 


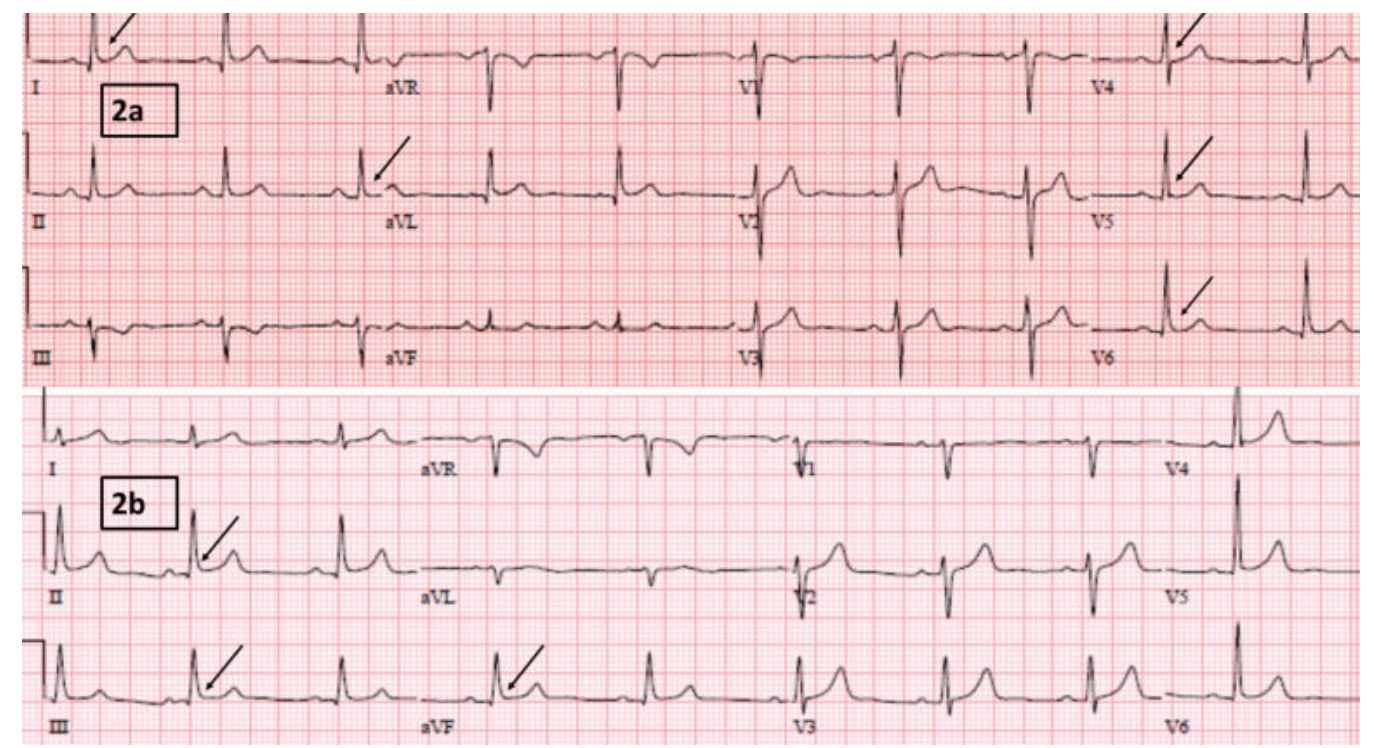

Fig. 2. (a) Lateral early repolarization pattern example. Arrows indicate QRS slurring with around 2 mm J point elevation followed by upsloping benign ST segment changes. (b) Inferior early repolarization pattern example. Arrows indicate QRS slurring with around $1 \mathrm{~mm} \mathbf{J}$ point elevation and a malignant type horizontal ST segment elevation is followed.

and percentages and, if appropriate, were compared with the Chi-square analysis. Univariate and later multivariate analysis was performed to determine the predictive value of significant and predetermined confounders on the JWP observations using the logistic regression model. A Receiver Operating Characteristic (ROC) curve was plotted in order to determine the diagnostic accuracy of a certain laboratory value. A $p$ value $<0.05$ was accepted statistically significant. Statistical analysis was performed using SPSS 16.0 (IBM Inc., Armonk, New York, USA).

\section{RESULTS}

Of 185 volunteers, 179 male subjects (mean age $34.9 \pm 7.9$ years) were included in our analyses after

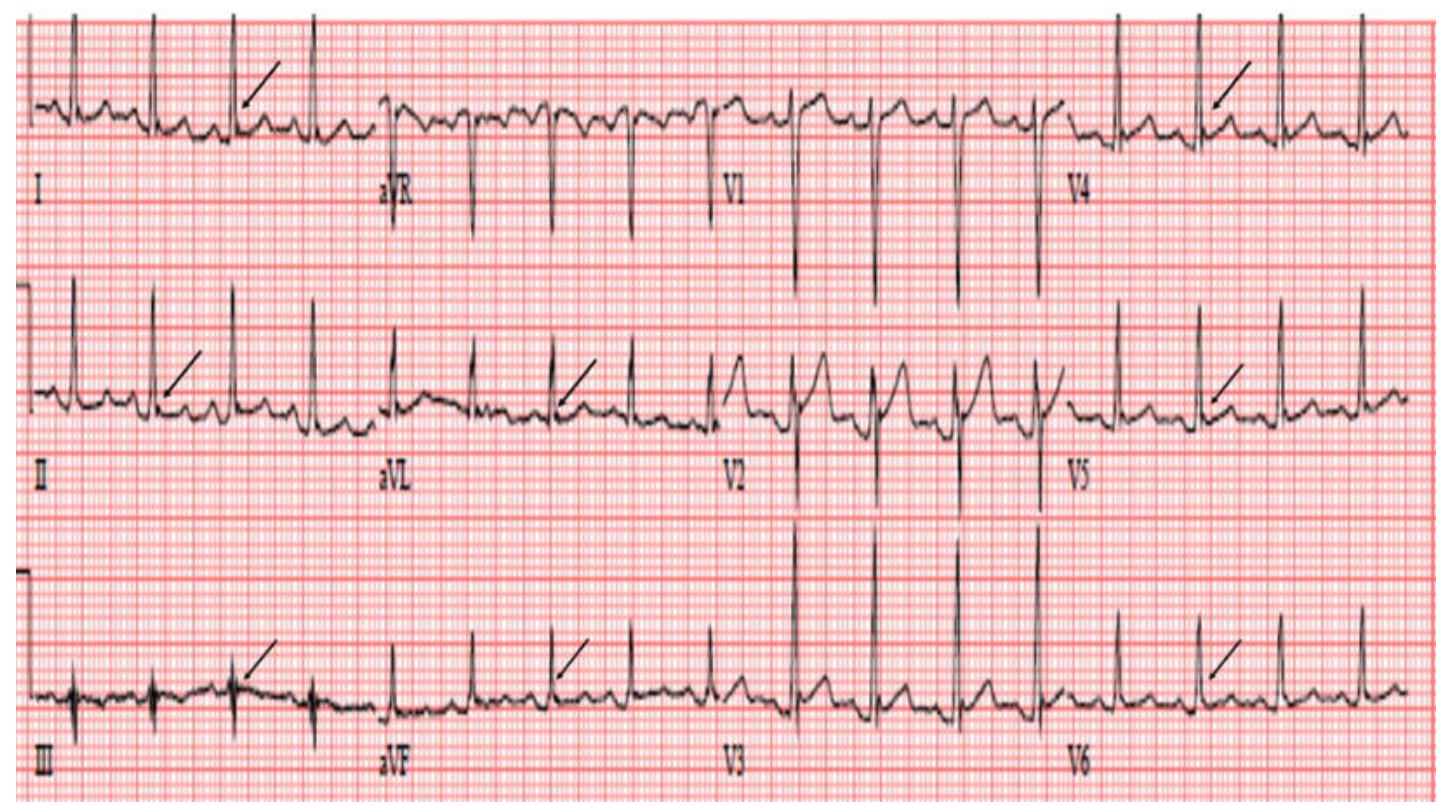

Fig. 3. Inferolateral early repolarization pattern. Arrows indicate QRS slurring with around $1 \mathrm{~mm} \mathbf{J}$ point elevation and a benign type upsloping ST segment elevation is followed in inferior leads and QRS notching on lateral leads followed by upslope ST elevations most evident on DI, DII, aVF, aVL, V4 to V5. 


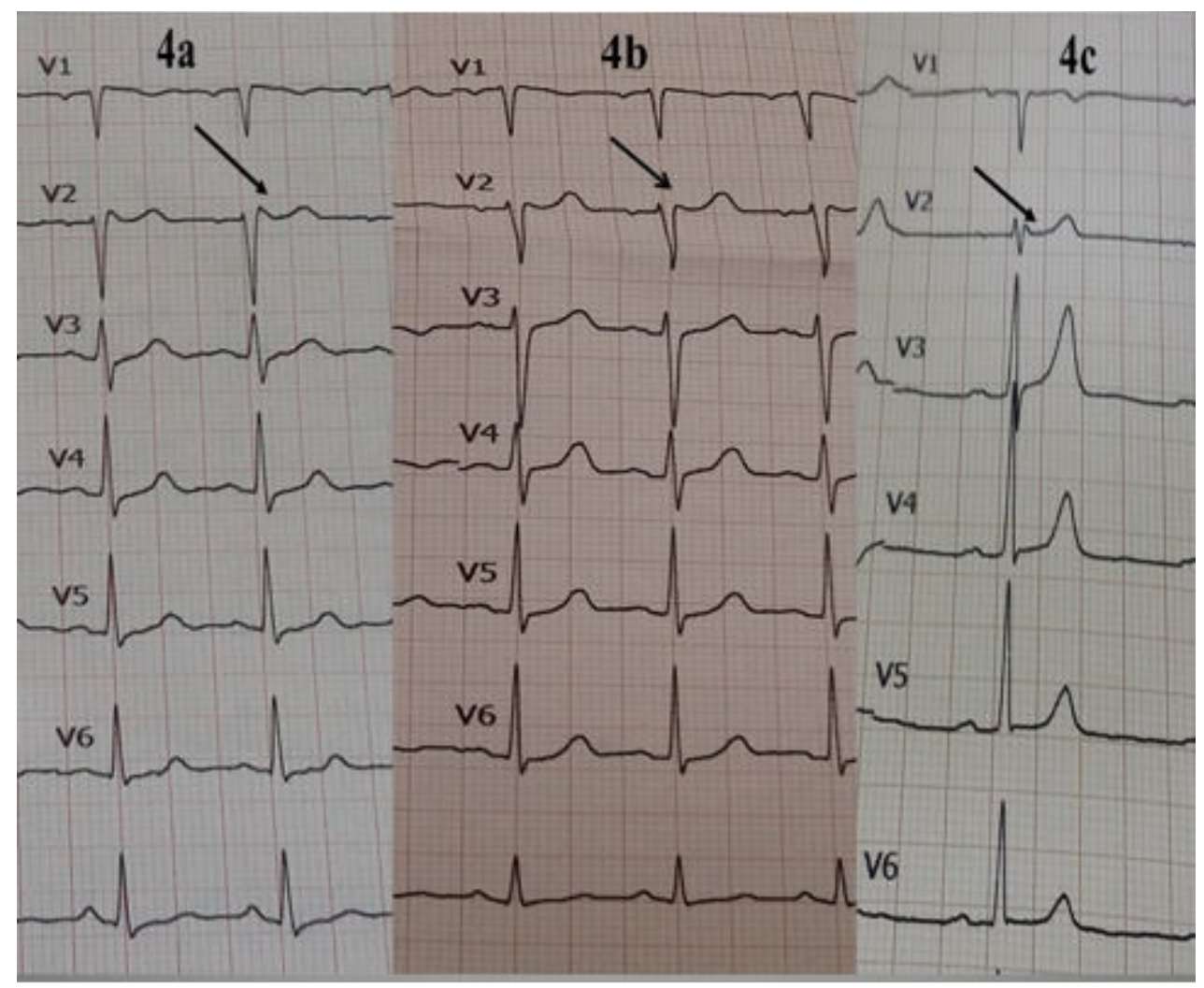

Fig. 4. Brugada-type-ECG-patterns revealed in our study. 4a: Type-2 Brugada pattern, 4b and c: Type-3 Brugada pattern. Arrowheads denote the diagnostic j-waves. No type-1 pattern was found.

the application of inclusion criteria. In total 48 JWPs $(26.8 \%)$ were detected on surface ECG; consisting of 3 BTEPs (1 Type-2, 2 type-3) and 45 ER patterns (22 lateral, 13 inferior and 10 of them were inferolateral ER) (Figs. 1 to 4). JWP (+) subjects were significantly younger, with a lower basal heart rate, longer PR interval and had significantly higher hs-CRP and testosterone levels compared with the ones without (Table 1). However, no significant association could be demonstrated with ESR, white blood cell count,

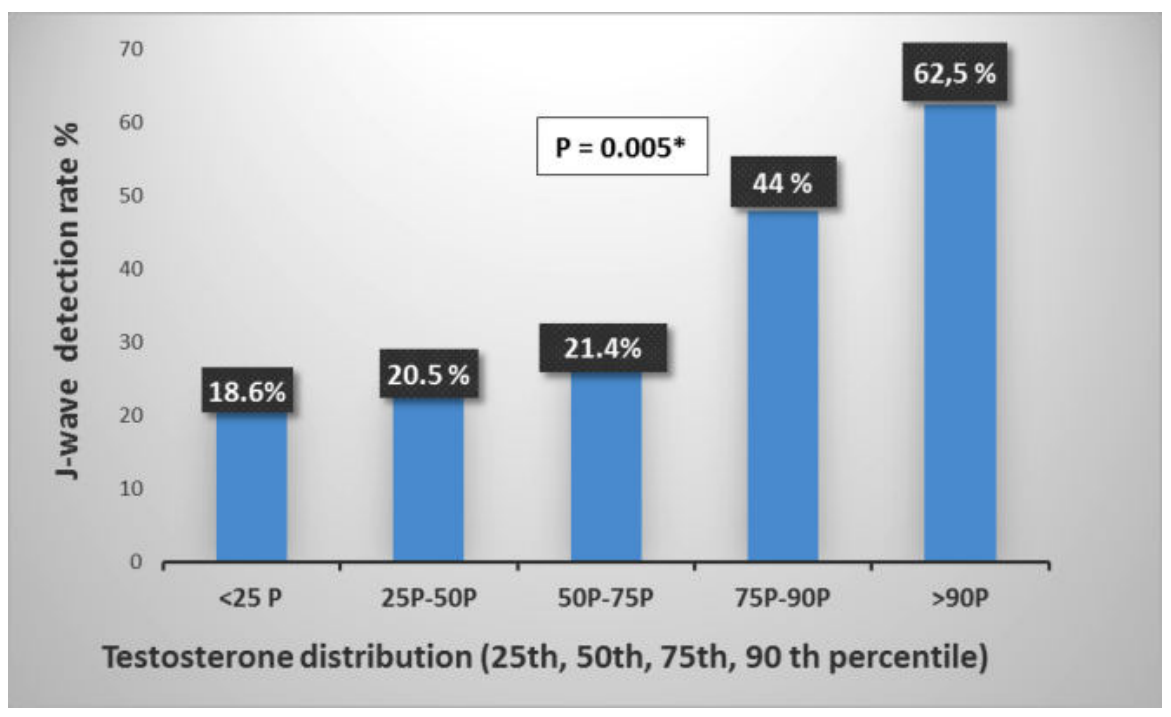

Fig. 5. The frequency of $\mathbf{J}$ wave patterns according to the testosterone percentiles Asterix denote a statistically significant and evidently higher $J$ wave patterns in the groups higher than $50^{\text {th }}$ percentile when compared with the low testosterone levels 
Table 1. Baseline characteristics of the subjects with and without J-wave patterns

\begin{tabular}{|c|c|c|c|}
\hline & $\begin{array}{c}\text { JWP (-) } \\
(n=131)\end{array}$ & $\begin{array}{l}\text { JWP (+) } \\
(n=48) \\
\end{array}$ & $p$ value \\
\hline Age (years) & $35.5 \pm 8.1$ & $33 \pm 5.8$ & 0.048 \\
\hline Weight (kg) & $83.1 \pm 11.6$ & $81.5 \pm 10.6$ & 0.42 \\
\hline Height (cm) & $176.2 \pm 5.6$ & $176.3 \pm 4.8$ & 0.82 \\
\hline Body mass index $\left(\mathrm{kg} / \mathrm{m}^{2}\right)$ & $26.7 \pm 3.3$ & $26.2 \pm 3.5$ & 0.40 \\
\hline \multicolumn{4}{|l|}{ ECG parameters } \\
\hline Heart rate (bpm) & $74 \pm 11.5$ & $68 \pm 10$ & $<0.001$ \\
\hline QTc duration (ms) & $404.1 \pm 18$ & $404 \pm 14.3$ & 0.89 \\
\hline PR duration (ms) & $153 \pm 20.3$ & $163.5 \pm 22$ & 0.01 \\
\hline QRS duration (ms) & $90.2 \pm 11$ & $92 \pm 10$ & 0.30 \\
\hline \multicolumn{4}{|l|}{ Laboratory results } \\
\hline Glucose (mg/dL) & $87.1 \pm 11.1$ & $85.9 \pm 10.5$ & 0.51 \\
\hline $\mathrm{BUN}(\mathrm{mg} / \mathrm{dL})$ & $29.2 \pm 7.2$ & $29.5 \pm 6.7$ & 0.75 \\
\hline Creatinine $(\mathrm{mg} / \mathrm{dL})$ & $0.91 \pm 0.12$ & $0.89 \pm 0.10$ & 0.28 \\
\hline Uric acid (mg/dL) & $5.3 \pm 1.01$ & $5.4 \pm 1.1$ & 0.53 \\
\hline Sodium (mmol/L) & $143.1 \pm 2.5$ & $143.1 \pm 2.4$ & 0.94 \\
\hline Potassium (mmol/L) & $4.5 \pm 0.3$ & $4.5 \pm 0.3$ & 0.96 \\
\hline Hemoglobin $(\mathrm{g} / \mathrm{dL})$ & $14.5 \pm 0.9$ & $14.4 \pm 0.9$ & 0.57 \\
\hline Platelet count $\left(10^{3} / \mu \mathrm{L}\right)$ & $232.9 \pm 57.9$ & $235.1 \pm 50.2$ & 0.81 \\
\hline $\mathrm{WBC}\left(10^{3} / \mu \mathrm{L}\right)$ & $5.97 \pm 1.4$ & $5.63 \pm 1.1$ & 0.13 \\
\hline Neutrophil $\left(10^{3} / \mu \mathrm{L}\right)$ & $3,15 \pm 1.03$ & $2.86 \pm 0.88$ & 0.08 \\
\hline Lymphocyte $\left(10^{3} / \mu \mathrm{L}\right)$ & $2.02 \pm 0.46$ & $1.891 \pm 0.52$ & 0.17 \\
\hline NLR $(\%)$ & $1.56 \pm 0.47$ & $1.63 \pm 0.68$ & 0.50 \\
\hline hsCRP (mg/L) & $1.6 \pm 1.7$ & $3.0 \pm 2.9$ & 0.004 \\
\hline $\operatorname{ESR}(\mathrm{mm} / \mathrm{h})$ & $6.7 \pm 4.6$ & $8.4 \pm 6.2$ & 0.07 \\
\hline Total cholesterol (mg/dL) & $182.5 \pm 34.3$ & $184.2 \pm 33.8$ & 0.78 \\
\hline $\mathrm{HDL}(\mathrm{mg} / \mathrm{dL})$ & $41.5 \pm 8.7$ & $42.1 \pm 9.8$ & 0.75 \\
\hline LDL (mg/dL) & $112.2 \pm 27.5$ & $112.1 \pm 26.3$ & 0.99 \\
\hline Triglycerides $(\mathrm{mg} / \mathrm{dL})$ & $140.9 \pm 78.4$ & $143.0 \pm 78.6$ & 0.87 \\
\hline $\mathrm{TSH}(\mathrm{mIU} / \mathrm{L})$ & $1.7 \pm 0.9$ & $1.8 \pm 0.96$ & 0.73 \\
\hline Vitamin D, 25-Hydroxy (ng/mL) & $12.8 \pm 6.03$ & $13.2 \pm 5.08$ & 0.73 \\
\hline Vitamin B12 (pg/mL) & $270.5 \pm 118.9$ & $305.9 \pm 113.6$ & 0.18 \\
\hline Total Testosterone (ng/dL) & $481.6 \pm 125.7$ & $556.4 \pm 165.3$ & 0.002 \\
\hline LDH (U/L) & $346.8 \pm 49.9$ & $341 \pm 62.1$ & 0.57 \\
\hline $\operatorname{Iron}(\mathrm{Fe})(\mu \mathrm{g} / \mathrm{dL})$ & $102.6 \pm 35.8$ & $89.2 \pm 57.5$ & 0.35 \\
\hline Ferritin (mg/L) & $92.1 \pm 70.8$ & $13.2 \pm 5.08$ & 0.79 \\
\hline Folate $(\mathrm{ng} / \mathrm{mL})$ & $7.58 \pm 1.8$ & $7.83 \pm 2.05$ & 0.45 \\
\hline Fibrinogen $(\mathrm{mg} / \mathrm{dL})$ & $270.3 \pm 89.4$ & $274.6 \pm 96.01$ & 0.83 \\
\hline
\end{tabular}


Table 2. Testosterone levels among the J-wave patterns

\begin{tabular}{|c|c|c|c|c|}
\hline \multirow[t]{2}{*}{ J-wave Pattern } & \multicolumn{3}{|c|}{ Testosterone levels } & \multirow[t]{2}{*}{$p$ value* } \\
\hline & Mean \pm SD & $\begin{array}{r}95 \% \\
\text { I }\end{array}$ & $\begin{array}{l}\text { lence } \\
\text { l }\end{array}$ & \\
\hline Inferolateral ER & $600.2 \pm 163.3$ & 483.3 & 717.1 & 0.005 \\
\hline Inferior ER & $593.4 \pm 201.6$ & 471.6 & 715.3 & \\
\hline Lateral ER & $520.6 \pm 145.5$ & 456.1 & 585.1 & \\
\hline ВTEP & $627.6 \pm 206.5$ & 114.6 & 1140.7 & \\
\hline
\end{tabular}

$\mathrm{ER}=$ early repolarization pattern, $\mathrm{BTEP}=$ Brugada type $\mathrm{ECG}$ pattern, ${ }^{*} \mathrm{P}$ value is for the statistical significance of the higher testosterone levels observed in inferior/inferolateral ER and BTEP compared with the lowest testosterone levels observed in lateral ER group.

neutrophil to lymphocyte ratio and uric acid levels. For the subgroup analyses and to efficiently define a probable dose-response effect with the testosterone levels, we divided the testosterone levels into $25^{\text {th }}, 50^{\text {th }}$, $75^{\text {th }}$ and $90^{\text {th }}$ percentiles and showed that significantly more JWPs were demonstrated after the $50^{\text {th }}$ percentile and significance continues as the testosterone percentiles rises, when compared with each other (Fig. 5). Among the JWPs, BTEPs have the highest mean testosterone value and it was significant when compared with JWP (-) population and it was followed by the inferior and inferolateral ER patterns with significantly higher testosterone levels (Table 2).
However, lateral ER patterns did not demonstrate any significant difference regarding the mean testosterone levels when compared with the JWP (-) subjects. In the ROC curve, the Area Under the Curve was determined 0.66 (95\% CI: 0.56-0.75) $(p=0.001)$ and a cut-off value for testosterone was determined as 629 $\mathrm{ng} / \mathrm{dl}$ with a sensitivity of $44 \%$ and a reasonable specificity of $86 \%$ to predict the presence of JWP (Fig. 6). In multivariate analysis, total testosterone level $>$ $629 \mathrm{ng} / \mathrm{dl}$ was significantly predicting a JWP on ECG, even outperforming age and hs-CRP levels with an OR of 4.57 (95\% CI 1.910-10.9, $p=0.001)$ (Table 3).

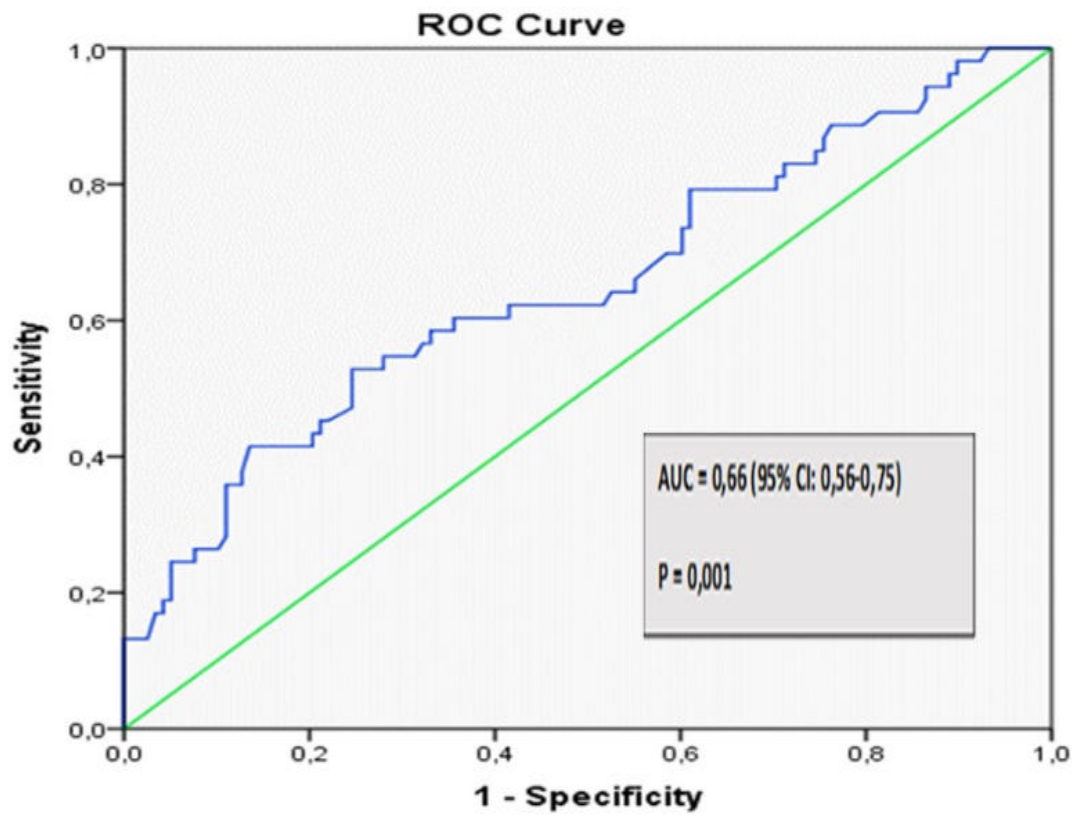

Fig. 6. ROC analysis to define the predictive value of higher testosterone levels and the presence of $\mathbf{J}$ wave pattern on ECG. ROC $=$ Receiver Operating Characteristics, AUC = Area Under the Curve, Cutt off value for total testosterone level : 629 ng/dL (sensitivity $44 \%$, specificity $86 \%$ ) 
Table 3. Multivariate regression model for the testosterone cut-off value determined in ROC analysis predicting the odds that the subject might demonstrate a JWP on ECG.

\begin{tabular}{lccc}
\hline Parameters & Odds ratio & $\mathbf{9 5 \%}$ confidence interval & $\boldsymbol{p}$ value \\
\hline Age & 0.95 & $0.90-1.02$ & 0.950 \\
hsCRP & $\mathbf{1 . 2 6}$ & $1.08-1.47$ & $\mathbf{0 . 0 0 4}$ \\
BMI & 0.97 & $0.85-1.11$ & 0.662 \\
Vitamin D & 1.01 & $0.93-1.08$ & 0.653 \\
TSH & 1.11 & $0.73-1.68$ & 0.620 \\
Testosterone value $\mathbf{8} \mathbf{6 2 9} \mathbf{~ n g / d L}$ & $\mathbf{4 . 5 7}$ & $\mathbf{1 . 9 1 0 - 1 0 . 9}$ & $\mathbf{0 . 0 0 1}$ \\
\hline
\end{tabular}

hsCRP $=$ high-sensitive-C-reactive peptide, $\mathrm{BMI}=$ Body mass index, $\mathrm{TSH}=$ thyroid stimulating hormone

\section{DISCUSSION}

In our study, a JWP prevalence of $27 \%$ and a BTEP percentage of $1.7 \%$ was consistent with the findings of the previous similar age and gender matched population based studies [12]. No type-1 BTEP was found. The ones with JWP were significantly demonstrating a higher vagal tone (relatively low basal heart rate, longer PR interval) compared with the ones without JWP, a finding also compatible with the previous population based studies and proposed mechanisms $[12,13,22]$. Our healthy male population gave out evidently higher prevalance than the general population for these relatively rare ECG findings however, it was the result of our design to increase the expected number of cases in order to perform significant statistical calculations. Testosterone demonstrated a dose response effect on the prevalence and type of JWPs. Significantly more JWPs were being observed in the higher levels of testosterone and suggestively high-risk patterns such as BTEP and inferior/inferolateral ER patterns were related with the highest percentile of testosterone distribution. In the ROC analysis a cut of testosterone value of $629 \mathrm{ng} / \mathrm{dl}$ were significantly found to be predictive of a JWP on ECG with a good specificity and a reasonable sensitivity. In the multivariate regression model, predetermined testosterone level of $629 \mathrm{ng} / \mathrm{dl}$ were evidently and significantly predicting the presence of JWP on the surface ECG and even outperforming previously known predictors of JWP and cardiac risk including young age and inflammation.

In J wave syndromes, main mechanism leading to ERs and Brugada pattern is explained by an outward shift in cardiac action potential repolarizing current due to a decrease in $\mathrm{Na}+$ or $\mathrm{Ca}+2$ channel currents or an increase in outward currents (Ito, IK-ATP, IK-ACh, or other) leading to a more negative intracellular ionic balance on the related myocardial sites giving rise to a transmural voltage gradient between endocardium and epicardium on partial regions of the heart leading to lethal ventricular arrhythmias [12].

\section{Clues about the possible role of the gonadal hormones on electrocardiogram}

It has formerly been demonstrated that, on average, adult men have shorter QT intervals than do women, but gender differences become apparent after the onset of puberty [23]. This gender difference is absent at birth and in young children [24]. Throughout puberty, the QTc interval in males shortens by $20 \mathrm{~ms}$, whereas the QTc of females remains unchanged, resulting in a $6 \%$ shorter QTc in males compared to females [25] Pecori-Geraldi et al. [26] compared the QTc in 26 men with hypogonadism with the QTc in 26 age-matched controls. They reported a higher prevalence of a prolonged QTc in hypogonadal men $(15 \%)$ than in controls $(0 \%)(p<0.05)$ and demonstrated normalization of the QTc after testosterone therapy. Similarly, a case-control study with 27 orchiectomized men with no exogenous testosterone therapy and 53 non-orchiectomized controls demonstrated that orchiectomized men had significantly longer JTc intervals (from the start of the $\mathrm{J}$ wave to the end of the $\mathrm{T}$ wave) than nonorchiectomized men [27]. In fertile women it was demonstrated that menstrual cycle influences QT interval and responses to drugs. During the follicular phase, when oestradiol rises, there is a greater 
sensitivity to potassium channel blockers (Ibutilide) resulting in a greater QT prolongation. During luteal phase progesterone seems to shorten QT interval. Furthermore, there are changes in autonomic tone resulting in higher level of noradrenaline (but not adrenaline or vagal tone) in luteal phase in respect with follicular phase [28]. Males manifest a greater transient outward potassium current (Ito)-mediated phase 1 notch in the right ventricular epicardium than females [29], however after puberty, the J point amplitude gets higher and the ST segment angle becomes steeper suggesting additive role of the everchanging hormonal status on the JWPs observed apart from the microstructural differences observed in males $[30,31]$. It has also been demonstrated that diurnal changes in the testosterone levels effect the augmentation or disappearance of the BTEPS observed in BS patients, even in the same day and night.

\section{Cellular effects of gonadal hormones on cardiac ion channels}

It has previously been demonstrated that sex steroid hormones exert their effects via transcriptional regulation and in order to do that, they bind to sex hormone receptors and then translocate into the nucleus leading to regulation of gene expression [32]. That means that, it was formerly thought that gonadal hormones need several hours or days to establish their effects. However, in the recent literature, new research challenged this idea and has shown that sex steroids might also acutely affect the cardiac ion channel activity PI3K/Akt/eNOS pathway. It has been shown that testosterone induced phosphorylation of the Ser/Thr kinase and endothelial nitric oxide (NO) synthase leads to NO -synthase-3 activation and production of NO [33]. NO leads to s-nitrosylation of cysteine residues on the channel underlying the slow delayed rectifier $\mathrm{K}+$ current (IKs) [34]. L-type Ca2+ current $(\mathrm{ICa}, \mathrm{L})$ is conversely suppressed by $\mathrm{NO}$ via a cGMP dependent pathway. Regulation of IKs and $\mathrm{ICa}, \mathrm{L}$ by testosterone is dose-dependent and leads to shortening of action potential duration and QT intervals $[32,33]$. In the contemporary literature emerging evidence accumulates about the nongenomic acute effects of sex steroids such as directly binding to IKs channel to modify its functions directly to a special site on channel and effecting its gating functions suggesting that even non-genomic actions of testosterone and progesterone on cardiac ion channels are likely to contribute to the gender differences in cardiac repolarization processes [35]. In a letter by Juhani-Junttila et al. [36], authors demonstrated a higher prevalence of ER patterns on the highest tertile of the testosterone levels consistent with our findings however they demonstrated a higher incidence of the lateral ER patterns with benign type upsloping ST elevations in their Finnish male population. Oppositely, we demonstrated that in Turkish male subjects, highest testosterone tertiles were associated with the inferior/inferolateral ER patterns or BTEPs which theoretically have the highest risk characteristics according to the former populationbased studies [13].

In our work, subclinical inflammatory parameter (hs-CRP) was also associated with an increased frequency of JWPs with a borderline significance as a secondary finding of our work and it was also consistent with the previously published data on the effects of inflammation and JWPs [37], yet testosterone levels outweighed this significance in the multivariate regression analysis revealing itself as a significantly more dominant risk factor.

\section{Limitations}

In this study we only considered the admittance surface ECG and the well-known dynamic character of the JWPs [12] might be the leading limitation for a probable underestimation. This aspect of the J-wave phenomenon will always be there in the clinical studies conducted on this concept because of its susceptibility to the ever changing vagal/hormonal tonus and environmental factors like temperature, diurnal vagal and hormonal changes and even by the food intake $[12,13]$. We tried to overcome this underestimation problem by trying to conduct our study on young and male volunteers and hypothetically increasing our expected JWP prevalence. Because of the highly influential JWP changes in the menstrual cycle period of women [29], we did not include female subjects in our study however it would be good to compare the doseresponse effects of male and female gonadal hormones on the ECG manifestations by a more complicated study design. It would also be better to look for the $\mathrm{Na}$ and $\mathrm{K}$ channel mutations in the JWP group for causal 
and additive definitions in spite of the fact that recent data shows sex hormones failure to effect the functions of mutant $\mathrm{Na}$ channels [38]. Even though our study design was cross-sectional, it might be good to follow the patients with highest percentile testosterone and JWP in the long term for any arrhythmic event and changes in JWP.

\section{CONCLUSION}

The prevalence of JWPs observed in young health Turkish males are consistent with the frequencies observed in other Caucasian population studies revealing more lateral ER and similar BTEP prevalence. Testosterone levels seemingly influence the prevalence of JWP observed in young healthy males with a dose-response relationship demonstrating the highest frequency and suggestively highest JWPs. This finding might be attributed to the experimentally demonstrated effects of sex-hormones on various cardiac ion channel functions taking part in the cardiac action potential and might be related to non-genomic direct effects on different races and geographical areas $[32,35]$. Larger, population-based studies with a long term follow up might be designed to elucidate the mechanistic pathways between the gonadal hormones and JWPs.

\section{Conflict of interest}

The author disclosed no conflict of interest during the preparation or publication of this manuscript.

\section{Financing}

The author disclosed that they did not receive any grant during conduction or writing of this study.

\section{REFERENCES}

1. Barnes AR, Katz LN, Levine SA, Pardee HEB, White PD, Wilson FN. The standardization of electrocardiographic nomenclature. J Am Med Assoc 1943;121:1347-9.

2. Osborn JJ. Experimental hypothermia: respiratory and blood $\mathrm{pH}$ changes in relation to cardiac function. Am J Physiol Content 1953;175:389-98.

3. Myers GB, Klein HA. Normal variations in multiple precordial leads. Am Heart J 1947;34:785-808.

4. Goldman MJ. RS-T segment elevation in mid- and left precordial leads as a normal variant. Am Heart J 1953;46:81720.

5. Klatsky AL, Oehm R, Cooper RA, Udaltsova N, Armstrong MA. The early repolarization normal variant electrocardiogram: correlates and consequences. Am J Med 2003;115:171-77.

6. Haïssaguerre M, Derval N, Sacher F, Jesel L, Deisenhofer I, de Roy L, et al. Sudden cardiac arrest associated with early repolarization. N Engl J Med 2008;358:2016-23.

7. Nam G-B, Kim Y-H, AntC zelevitch. Augmentation of J waves and electrical storms in patients with early repolarization. $\mathrm{N}$ Engl J Med 2008;358:2078-9.

8. Tikkanen JT, Anttonen O, Junttila MJ, Aro AL, Kerola T, Rissanen HA, et al. Long-term outcome associated with early repolarization on electrocardiography. $\mathrm{N}$ Engl J Med 2009;361:2529-37.

9. Haruta D, Matsuo K, Tsuneto A, Ichimaru S, Hida A, Sera N, et al. Incidence and prognostic value of early repolarization pattern in the 12-lead electrocardiogram. Circulation 2011;123:2931-7.

10. Antzelevitch C, Brugada P, Borggrefe M, Brugada J, Brugada R, Corrado D, et al. Brugada Syndrome: Report of the Second Consensus Conference. Circulation 2005;111:659-70.

11. Kamakura S, Ohe T, Nakazawa K, Aizawa Y, Shimizu A, Horie M, et al. Long-term prognosis of probands with Brugadapattern ST-elevation in leads V1-V3. Circ Arrhythm Electrophysiol 2009;2:495-503.

12. Antzelevitch C. J wave syndromes: molecular and cellular mechanisms. J Electrocardiol 2013;46:510-8.

13. Macfarlane PW, Antzelevitch C, Haissaguerre M, Huikuri H V., Potse M, Rosso R, et al. The early repolarization pattern: a consensus paper. J Am Coll Cardiol 2015;66:470-7.

14. Bozkurt A, Yas D, Seydaoglu G, Acartürk E. Frequency of Brugada-type ECG pattern (Brugada sign) in southern Turkey. Int Heart J 2006;47:541-7.

15. Hünük B, Kepez A, Erdoğan O. The prevalence of early repolarization variant in Turkish male subjects: a clinical single center study. Turk Kardiyol Dern Ars 2012;40:409-13.

16. Rollin A, Maury P, Bongard V, Sacher F, Delay M, Duparc A, et al. Prevalence, prognosis, and identification of the malignant form of early repolarization pattern in a populationbased study. Am J Cardiol 2012;110:1302-08.

17. Di Diego JM, Antzelevitch C. Inferolateral J-wave syndromes: A reflection of abnormal repolarization, depolarization, or both? Heart Rhythm 2018. doi:10.1016/j.hrthm.2018.11.020.

18. Antzelevitch C, Yan G-X, Ackerman MJ, Borggrefe M, Corrado D, Guo J, et al. J-Wave syndromes expert consensus conference report: Emerging concepts and gaps in knowledge. Europace 2017;19:665-94

19. Benito B, Sarkozy A, Mont L, Henkens S, Berruezo A, Tamborero D, et al. Gender differences in clinical manifestations of Brugada syndrome. J Am Coll Cardiol 2008;52:1567-73.

20. James AF, Choisy SCM, Hancox JC. Recent advances in understanding sex differences in cardiac repolarization. Prog Biophys Mol Biol 2007;94:265-319.

21. Shimizu W, Matsuo K, Kokubo Y, Satomi K, Kurita T, Noda $\mathrm{T}$, et al. Sex hormone and gender difference--role of testosterone 
on male predominance in Brugada syndrome. J Cardiovasc Electrophysiol 2007;18:415-21.

22. Patton KK, Ellinor PT, Ezekowitz M, Kowey P, Lubitz SA, Perez M, et al. Electrocardiographic early repolarization. Circulation 2016;133:1520-9.

23. Nakagawa M, Ooie T, Ou B, Ichinose M, Takahashi N, Hara $\mathrm{M}$, et al. Gender differences in autonomic modulation of ventricular repolarization in humans. J Cardiovasc Electrophysiol 2005; 16:278-84.

24. Stramba-Badiale M, Spagnolo D, Bosi G, Schwartz PJ. Are gender differences in QTc present at birth? MISNES Investigators. Multicenter Italian Study on neonatal electrocardiography and sudden infant death syndrome. Am J Cardiol 1995;75:1277-8.

25. Rautaharju PM, Zhou SH, Wong S, Calhoun HP, Berenson GS, Prineas R, et al. Sex differences in the evolution of the electrocardiographic QT interval with age. Can J Cardiol 1992;8:690-5.

26. Pecori-Giraldi F, Toja PM, Filippini B, Michailidis J, Scacchi M, Stramba-Badiale M, et al. Increased prevalence of prolonged QT interval in males with primary or secondary hypogonadism: a pilot study. Int J Androl 2010;33:e132-8.

27. Bidoggia H, Maciel JP, Capalozza N, Mosca S, Blaksley EJ, Valverde E, et al. Sex differences on the electrocardiographic pattern of cardiac repolarization: possible role of testosterone. Am Heart J 2000;140:678-83.

28. Nakagawa M, Ooie T, Takahashi N, Taniguchi Y, Anan F, Yonemochi $\mathrm{H}$, et al. Influence of menstrual cycle on QT interval dynamics. Pacing Clin Electrophysiol 2006;29:607-13.

29. Di Diego JM, Cordeiro JM, Goodrow RJ, Fish JM, Zygmunt AC, Pérez GJ, et al. Ionic and cellular basis for the predominance of the Brugada syndrome phenotype in males. Circulation 2002;106:2004-11.
30. Ezaki K, Nakagawa M, Taniguchi Y, Nagano Y, Teshima Y, Yufu K, et al. Gender differences in the ST segment: effect of androgen-deprivation therapy and possible role of testosterone. Circ J 2010;74:2448-54.

31. Nakagawa M, Takahashi N, Watanabe M, Ichinose M, Nobe $\mathrm{S}$, Yonemochi $\mathrm{H}$, et al. Gender differences in ventricular repolarization: terminal $\mathrm{T}$ wave interval was shorter in women than in men. Pacing Clin Electrophysiol 2003;26:59-64.

32. Yang P-C, Kurokawa J, Furukawa T, Clancy CE. Acute effects of sex steroid hormones on susceptibility to cardiac arrhythmias: a simulation study. PLoS Comput Biol 2010;6:e1000658.

33. Bai C-X, Kurokawa J, Tamagawa M, Nakaya H, Furukawa T. Nontranscriptional regulation of cardiac repolarization currents by testosterone. Circulation 2005;112:1701-10.

34. Asada K, Kurokawa J, Furukawa T. Redox- and calmodulindependent S-nitrosylation of the KCNQ1 channel. J Biol Chem 2009;284:6014-20.

35. Kurokawa J, Furukawa T. Non-genomic action of sex steroid hormones and cardiac repolarization. Biol Pharm Bull 2013;36:812.

36. Juhani-Junttila M, Tikkanen JT, Porthan K, Oikarinen L, Jula A, Kenttä T, et al. Relationship between testosterone level and early repolarization on 12-lead electrocardiograms in men. JACC 2013;62:1633-4.

37. Hussein AA, Gottdiener JS, Bartz TM, Sotoodehnia N, DeFilippi C, See V, et al. Inflammation and sudden cardiac death in a community-based population of older adults: The Cardiovascular Health Study. Heart Rhythm 2013;10:1425-32.

38. Yang G, Liu J, Wang Y, Du Y, Ma A, Wang T. Lack of influence of sex hormones on Brugada syndrome-associated mutant Nav1.5 sodium channel. J Electrocardiol 2019;52:82-7. 